Revue

Revue de l'histoire des religions

de Ihistoire des religions

$1 \mid 2018$

Varia

\title{
Rita HERMON-BELOT, Aux sources de l'idée laïque. \\ Révolution et pluralité religieuse
}

Paris, Odile Jacob, 2015

Caroline Chopelin-Blanc

\section{OpenEdition}

Journals

Édition électronique

URL : http://journals.openedition.org/rhr/8887

DOI : 10.4000/rhr.8887

ISSN : 2105-2573

Éditeur

Armand Colin

Édition imprimée

Date de publication : 1 mars 2018

Pagination : 186-189

ISBN : 978-2-200-93166-7

ISSN : 0035-1423

\section{Référence électronique}

Caroline Chopelin-Blanc, « Rita Hermon-Belot, Aux sources de l'idée laïque. Révolution et pluralité religieuse », Revue de l'histoire des religions [En ligne], 1 | 2018, mis en ligne le 20 mars 2018, consulté le 15 janvier 2021. URL : http://journals.openedition.org/rhr/8887 ; DOI : https://doi.org/10.4000/rhr 8887

Ce document a été généré automatiquement le 15 janvier 2021.

Tous droits réservés 


\section{Rita HERMON-BELOT, Aux sources de l'idée laïque. Révolution et pluralité religieuse}

Paris, Odile Jacob, 2015

Caroline Chopelin-Blanc

\section{RÉFÉRENCE}

Rita HERMON-BELOT, Aux sources de l'idée laïque. Révolution et pluralité religieuse, Paris, Odile Jacob, 2015, 267 p., 24,90 €, ISBN 978-2-7381-3338-0.

1 Cet ouvrage est une synthèse des recherches menées par Rita Hermon-Belot, directrice d'études à l'EHESS, sur la pluralité religieuse pendant la période révolutionnaire. Il s'adresse à un large public, à toute personne se questionnant sur la genèse de la laïcité, plus précisément sur les origines révolutionnaires de l'idée laïque. L'A. adopte une perspective inédite, en relisant l'histoire politique et religieuse de la Révolution (1789-1799) sous l'angle de la pluralité religieuse. Elle part d'une préoccupation française très actuelle, le fait que la laïcité soit interrogée, pour certains menacée, par la coexistence, parfois perçue comme très difficile, de religions de traditions différentes : les confessions chrétienne, juive et musulmane. L'A. fait le rappel, qui peut paraître surprenant aux yeux du citoyen $d u x x^{\mathrm{e}}$ siècle, que les enjeux liés à la pluralité religieuse, loin d'être nouveaux, sont anciens en France, remontant, si l'on se borne à l'époque moderne, aux XVI ${ }^{\mathrm{e}}$ et XVII ${ }^{\mathrm{e}}$ siècles avec la constitution de minorités protestantes non négligeables.

2 En faisant une synthèse de l'historiographie, elle montre que la pluralité fait «partie de la genèse » de la laïcité au moment de la Révolution française (1789-1799). En effet, la Révolution a bouleversé toute réflexion sur la pluralité religieuse en France en la liant inextricablement à la question de "la liberté des cultes ", c'est-à-dire à la liberté de l'exercice public de toute religion. Voici les éléments de réponse principaux: 1/ la 
Révolution a ancré la liberté religieuse dans les droits individuels, et donc universels ; $2 /$ en créant cette catégorie des "cultes", elle a fait de ceux-ci les interlocuteurs essentiels de l'État en matière religieuse ; 3 / toutefois, c'est à l'État qu'elle a confié le monopole de l'espace commun, public; 4 / en échouant à constituer une religion civile, la Révolution a rendu impossible la "rencontre universelle" des citoyens dans le religieux et l'a déplacée vers le politique, transfert essentiel dans lequel s'enracine l'idée laïque ; 5/ enfin, elle a accéléré la sécularisation et la neutralisation des grands domaines de l'activité sociale (l'assistance et l'instruction publique) par l'État, autre germe de l'idée laïque.

Pour étayer sa démonstration, l'A. a choisi un plan chronologique. L'ouvrage est découpé en six chapitres. Le premier chapitre, "L"inauguration ", est centré sur la discussion des 22 et 23 août 1789 qui a abouti à l'adoption de l'article $\mathrm{X}$ de la Déclaration des droits de l'homme et du citoyen. L'analyse de cahiers de doléances de bailliages comptant des minorités religieuses - calvinistes, luthériennes et juives montre qu'à l'aube de la Révolution existe un « déficit particulièrement frappant de toute culture de la pluralité dans le royaume de France ", même dans les régions marquées par la coexistence religieuse. Les réactions quant à la visibilité, la " publicité », du culte en sont le révélateur. Pour toutes les confessions, il est évident que seule la "religion dominante », à savoir le catholicisme du roi, bénéficie de cette visibilité, et que la pratique des autres confessions et même des autres courants catholiques, tels que le jansénisme, soit reléguée dans l'obscurité. Néanmoins la Déclaration accomplit « un pas immense » en ce qu'elle attribue des droits égaux à tous les Français sans différenciation religieuse et établit la liberté de religion.

Dans le chapitre 2, «La liberté des cultes : un projet de la Révolution », l'A. s'attarde sur les débats de la Constituante relatifs aux droits civils et politiques des protestants et des juifs. Elle mène une réflexion très intéressante, également très actuelle, sur la confrontation entre droits collectifs, appartenant aux communautés, notamment juives, hérités de l'Ancien Régime, et droits individuels, dont se réclame le nouveau régime, et plus largement sur l'opposition entre particularisme et universalisme. L'âpreté des débats montre la difficulté, sur les bancs de l'Assemblée et au sein même des communautés juives, à penser en termes universels.

Le chapitre 3, " Au vu et au su: le culte visible ", revient sur la question centrale de la visibilité. En effet, la Constitution garantit bien à tout individu « la liberté d'exercer le culte religieux auquel il est attaché ", sans affirmer pour autant le caractère public de l'expression religieuse. C'est la définition même de l'expression de «liberté des cultes " qui est ici interrogée et difficilement cernée, parce que variant considérablement en fonction de l'appartenance religieuse, des traditions, des conditions imposées par la législation passée. Ce qui ne laisse pas d'étonner est que la sortie de l'invisibilité n'est pas sans poser de réticences aux minorités elles-mêmes, particulièrement juives. Cette question de la libre expression des appartenances religieuses explique la virulence du débat sur la «religion nationale » qui agite la Constituante en août 1789 et au printemps 1790. L'enjeu est double : à la fois symbolique et politique, c'est-à-dire relatif au monopole du culte public. Ce débat illustre les limites conceptuelles de l'idée laïque en 1790-1791, c'est-à-dire les difficultés des contemporains, même des esprits les plus ouverts tels qu'un Grégoire, à penser l'idée d'une pratique plurielle visible par tous.

Dans le chapitre 4 "La liberté des cultes dans ses véritables termes", l'A. examine la mise en œuvre de cette liberté des cultes dans le cadre de l'application de la 
Constitution civile du clergé, ensemble de réformes religieuses adoptées par la Constituante en juillet 1790, et du décret de mai 1791 qui donne le droit aux prêtres refusant la Constitution civile de célébrer la messe dans les églises constitutionnelles. De manière constante, en 1791 et 1792, dans les débats parlementaires, le principe de la liberté des cultes est défendu. L'A. montre plus particulièrement comment les discussions quant aux mesures à prendre à l'encontre des prêtres réfractaires, ayant refusé le serment à la loi, la nation et le roi imposé par la Constitution civile du clergé, questionnent l'enjeu de la pluralité religieuse, celle-ci concernant de plein fouet la majorité, catholique, et plus seulement les minorités protestantes et juives. Cette liberté, devenue "sacrée", est désormais promue au rang de norme légale et universelle mais elle ne fait pas encore partie intégrante d'une vision commune et partagée de la pluralité religieuse.

7 Toutefois, pendant les deux années suivantes, 1793 et 1794, un retournement - objet du $5^{2}$ chapitre - se produit : la liberté des cultes devient un "danger pour la Révolution » dans la mesure où elle aboutit à réduire au silence tout culte. Analysant «l'onde déchristianisatrice », l'A. souligne que l'argument de la pluralité et de la liberté des cultes est utilisé avec force par les pourfendeurs de la déchristianisation: conformément au principe de l'égalité des cultes, la déchristianisation a pour objectif premier d'éviter la domination d'un culte sur les autres. La problématique de la clandestinité - étroitement liée bien sûr à celle de la visibilité -, jusqu'alors surtout réservée aux minorités protestantes et juives, touche à son tour les catholiques, les réfractaires d'abord contraints rapidement à la clandestinité, les constitutionnels ensuite qui subissent de plein fouet les mesures déchristianisatrices. Finalement «1[a] première expérience de l'égalité aura [...] été celle de l'égalité face à une égale répression ", cette affirmation pouvant s'appliquer à tous les groupes religieux, y compris catholiques.

8 Le chapitre 6, intitulé «L'introuvable religion civile " (juillet 1794- novembre 1799), traite de ce moment considéré a posteriori comme la première séparation de l'Église et de l'État»: «La République ne reconnaît, ni ne subventionne aucun culte». L'A. souligne l'incapacité, tant conceptuelle que politique, des acteurs de l'État révolutionnaire à mettre en place une religion civile, à savoir un ensemble de codes destinés à rassembler les citoyens au-delà de leurs différences confessionnelles.

9 En ouverture de sa conclusion, l'A. insiste sur «l'œuvre inachevée de la Révolution française en matière de liberté des cultes » : d'abord, la " démarche de reconnaissance » à l'œuvre pendant la Révolution française et traversant un long XIX ${ }^{\mathrm{e}}$ siècle, qui n'aboutit qu'en 1905 ; ensuite, le "legs polémique ", la liberté des cultes étant interprétée comme un progrès essentiel par les uns, comme une production satanique par les autres.

10 Rappelons que l'ouvrage s'adresse à un large public, sinon au grand public. Ce qui explique en grande partie le renvoi de l'appareil de notes en fin et sa relative brièveté (peu de références à des sources primaires, des références bibliographiques parfois peu actualisées), ou encore la simplification de certaines analyses, ainsi la "déchristianisation ", terme dont l'usage est de plus en plus remis en question par les historiens de la Révolution parce que son ampleur fut très variable d'un territoire à l'autre en raison notamment de l'absence de cohérence dans les réactions des autorités.

11 Il n'en demeure pas moins que la lecture de cet ouvrage s'avère très stimulante par la nouveauté de son approche, par la résonance actuelle des débats évoqués, des problématiques soulevées, des défis posés, notamment l'opposition entre majorité et 
minorités, entre l'universel et le particulier, entre la visibilité de la pratique religieuse et son exercice clandestin ou de moins discret. L'A. montre bien la complexité des réactions, entre les groupes religieux mais aussi, ce qui est souvent plus inattendu, en leur sein même, et souligne à plusieurs reprises la difficulté propre à la culture politique révolutionnaire française de concevoir et d'admettre la confrontation d'opinions divergentes, peut-être en raison de son obsession de l'unité et de l'unanimité. Ne serait-ce pas une obsession qui perdurerait encore aujourd'hui et expliquerait, pour partie, les difficultés à penser plus sereinement une laïcité adaptée à notre pluralité religieuse actuelle?

\section{AUTEURS}

\section{CAROLINE CHOPELIN-BLANC}

Laboratoire de recherches historiques Rhône-Alpes. 